\title{
Impact and ricochet of a high-speed rigid projectile from an air-water interface
}

\author{
B Farouk ${ }^{1 *}$, H Bassindowa', S Segletes ${ }^{2}$ \\ 1. Mechanical Engineering Dept., Drexel University, \\ Philadelphia PA USA \\ 2. Impact Physics, Army Research, Aberdeen MD USA
}

\begin{abstract}
A numerical study on a rigid projectile (sphere) ricocheting off a water layer is presented in this paper. The time-dependent three-dimensional simulations are carried out for the impact of a solid metal sphere (with radius r) on a quiescent air-water interface. Three types of metal spheres with specific gravity $(\sigma)$ values ranging from 7.8 to 2.7 (steel, titanium and duralumin) were considered. The numerical results are compared with analytical solutions and experimental data of the ricochet problem available in the literature. A given range of projectile impact velocity $\left(V_{i}\right)$ are considered with varying impact angles to determine the critical angle of impact $\theta_{c r}$ - as a function of the Froude number $\left(F r=V_{i}^{2} / r g\right)$ and $\sigma$. A correlation in the form of $\theta_{c r}=f(F r, \sigma)$ is proposed for the ricochet of a solid sphere from an airwater interface.
\end{abstract}

\section{INTRODUCTION}

The phenomenon of ricochet of a projectile off the free surface of water was well known from at least the time of the Battle of Trafalgar, 1805 (1) when the range of ship-mounted cannons was increased by aiming the cannon sphere so that it would ricochet off the sea surface. Most ricochets are caused by accident and while the force of the deflection decelerates the projectile - it can still be energetic and almost as dangerous as before the deflection. The likelihood of ricochet is dependent on many factors, including the projectile shape and size, the projectile material, spin, velocity (and distance), target material and the angle of incidence (2).

The projectile construction has a major effect in determining both the likelihood of ricochet as well as where the projectile will travel afterward. Bullets are more likely to ricochet off flat, hard surfaces such as concrete or steel, but a ricochet can occur on almost any surface, including grassy soil, given a flat enough angle of impact of the projectile. Though it may not be intuitive, bullets/projectiles easily ricochet off water (3): compare the stone skipping phenomenon observed in ponds and lakes.

Figure 1 below shows the wetted area of a sphere at various depths of immersion during oblique impact on an air-water interface following (3). In order to study the mechanism of ricochet and the form of cavity associated with entry at glancing angles a number of shots were made by firing $7.62 \mathrm{~cm}(3.0 \mathrm{inch})$ ebonite and duralumin spheres from a catapult and $2.54 \mathrm{~cm}(1.0 \mathrm{inch})$ steel spheres from a gun. The trajectories and displacement-time curves were plotted, and exit and entry angles and velocities (if ricochet occurred were recorded (3).

*Corresponding Author: bfarouk@drexel.edu 


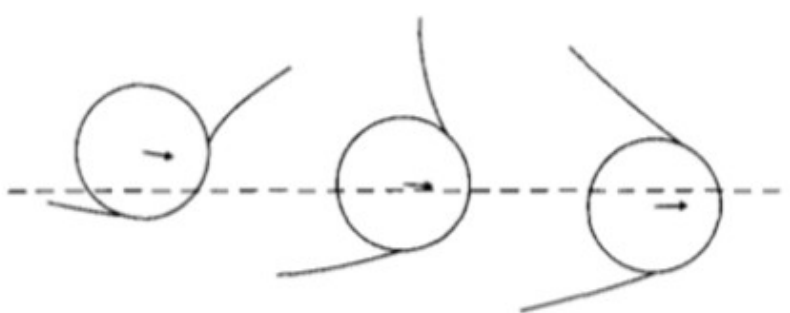

Figure 1. The shape of the water surf ace around a sphere at various states of oblique impact (3)

An early theory of ricochet was proposed by Birkhoff et al. (2) and detailed predictions from it are given by Johnson and Reid (4). The theory predicts the greatest or critical angle of attack at a liquid surface, $\theta_{c r}$ for a uniform solid sphere to undergo ricochet. It appears from experimental observations that the water pressure must act over a considerably greater area than that assumed by (2) The latter theory is unable to account for some of the phenomena associated with ricochet including the effect of spin and of the linear speed of the projectile on that impact angle (i.e., the angle between the launch direction and the water surface) which is the largest for which a single ricochet will occur - known as the critical angle. Hutchings (5) proposed a theory of ricochet which permits the effect of projectile spin to be accounted for. This effect was not explained by previous theories.

The critical angles for ricochet for a sphere and for a spinning cylinder were calculated, and the theory of the spinning cylinder was applied to the Wallis "bouncing bomb" developed during World War II (6). The concept originated by the British engineer Wallis (1942) described an interesting method of attack in which a weapon would be bounced (ricocheted) across water until it struck its target, then sinking to explode underwater, much like a depth charge. German hydro-electric dams had been identified as important bombing targets before the outbreak of World War II but existing bombs and bombing methods had little effect on them, as torpedo nets protected them from attack by conventional torpedoes and a practical means of destroying them had yet to be devised. Bouncing the weapon across the surface allowed it to be aimed directly at its target, while avoiding underwater defenses, as well as some above the surface, and such a weapon took advantage of the "bubble pulse" effect typical of underwater explosions, greatly increasing its effectiveness.

The Rayleigh formula (7) was applied by Hutchings to a spherical projectile and to a spinning cylindrical projectile. This theory predicted similar critical angles for ricochet for a sphere and for a cylinder without spin. The Rayleigh pressure distribution permitted the influence of projectile spin on ricochet to be deduced and predicted the increased critical angle. Rebound velocity and range of a projectile with back-spin, was utilized by Wallis (6) in the design of his bouncing bomb. This effect could not be accounted for by the Birkhoff et al. theory (2). A critical shortcoming of some of the earlier work (5) was that they ignored the effect of the Froude number $\left(F r=V_{i}^{2} / r g\right)$ on the critical angle of ricochet $\theta_{c r}$ where $V_{i}$ is the impact speed, $r$ is the radius of the sphere and $g$ is the acceleration due to gravity. 
Ricochet of projectiles against water is defined as an impact or a rebound such that at no time was the projectile fully below the water surface (4). However, when using sand as the target medium, it is found that debris is more likely to come out of the sand after an impact [5]. Furthermore, the debris is able to stand on a sand surface, while it sinks when it is placed on a water surface. Ricochet from an air-water interface has similarities to other fluid-structure impact cases e.g. ditching of airplanes. Experimental data are available in a limited number of studies on the ricochet of projectiles from water surface (1).

Ricochet phenomenon occurs when object strikes the surface of a medium, say water, which causes the molecules of water to move faster than it can rearrange itself in a microscopic scale. This causes the molecules to resist the object striking the surface which can cause a lift reaction force capable of bouncing off the object when certain conditions are met (8). A recent study (9) was set to investigate effect of sea waves on 0.50 caliber bullet ricocheting off sea waters. The study was intended to determine hazard zones due to uncontrolled ricocheting rounds due to the effect waves will have on the trajectory and direction of the rounds. In the study by (10), the temperature effect on sphere ricochet on sand was investigated through experimental and FEM modeling. They found that as the temperature of the sand increases, the shear stress acting by the sand particles on the sphere decreases which increases the sphere's penetration depth. This means that the resistivity of the sand decreases and more kinetic energy is lost increases due to friction and the speed of the ricocheted sphere decreases. (11) Used the source panel numerical method to study the impact and ricochet problems of arbitrary-shaped water-entry bodies, and they tested their method with a disk cylinder and two ogives and compared results with experimental and other numerical methods with good agreements.

Numerical calculations were used by (12) to investigate the effect of changing initial conditions (inclination angle, attack angle and velocity) of a vehicle entering a water air interface on the angular acceleration, angular velocity and displacement. They carried a smallscale experiment which verified the simulation results. Their results show that small inclination angle, large velocity, and negative attack angle favor the ricochet phenomenon. The problem of water impact of a body on free-surface is investigated by (13), where an open source code SPHysics2D that employs the SPH (Smoothed-Particle Hydrodynamics) was used. The model was tested by simulating still water as well as the dam-break problem and results were compared with available data. Then the model was used to successfully simulate the impact of a body on free-surface for different impact angles and velocities.

In this work, we present numerical results of the ricochet of a solid rigid sphere that impacts an air-water interface with a forward velocity. A critical shortcoming of some of the earlier work (5) was that the effect of the Froude number $\left(F r=V_{i}^{2} / r g\right)$ on the critical angle of ricochet $\theta_{c r}$ was ignored where $V_{i}$ is the impact speed, $\mathrm{r}$ is the radius of the sphere and $g$ is the acceleration due to gravity. In this work we clearly delineate the effect of the $F r$ and $\sigma$ (the specific gravity of the sphere material) on the ricochet behavior of solid spheres impacting an air-water interface. 


\section{PROBLEM DESCRIPTION}

Since ricochet related experiments are costly, time-consuming and limited in obtaining data - numerical simulation is an attractive alternative for studying the high-speed impact and the ricochet phenomenon. In this paper, a fully three-dimensional time-dependent numerical study on a rigid spherical projectile impact on an air-water interface is presented. The impact of a metal sphere of diameter $2.0 \mathrm{~cm}$ is considered for the present simulations. Well defined initial conditions (size and material of the rigid body, physical values of the fluids, air and water) are considered for the simulations. The sphere center is initially within the air zone and located at about $2.0 \mathrm{~cm}$ from the left boundary of the computational domain and at about $1.5 \mathrm{~cm}$ above the liquid surface. The rigid sphere impacts a quiescent air-water interface. The computational domain considered has a length $\mathrm{Lx}=60.0 \mathrm{~cm}$. For the threedimensional domain (with gravity acting in the $-\mathrm{z}$ direction), the water-depth $\mathrm{Lz}-\mathrm{W}=5.0$ $\mathrm{cm}$, and the air depth Lz-a $=5.0 \mathrm{~cm}$ having a width Ly $=10.0 \mathrm{~cm}$ (see Figure 2). The projectile (parallel to the $\mathrm{x}-\mathrm{z}$ plane) is located close to the air-water interface about $\mathrm{x}=1.0$ $\mathrm{cm}$ from the left edge and along the middle of the width of the layer, $\mathrm{y}=5 \mathrm{~cm}$. The combined air-water domain considered is $60.0 \mathrm{~cm} \mathrm{x} 10.0 \mathrm{~cm} \mathrm{x} 10.0 \mathrm{~cm}(x \times y \times z)$.

The projectile velocity components $(\mathrm{Vx}$ and $\mathrm{Vz})$ are chosen such that the resultant impact velocity $\mathrm{V}_{i}=\sqrt{V_{x}^{2}+V_{y}^{2}}$ is parallel to the inclination angle $\theta$ of the projectile (measured from the horizontal axis $x$ passing through the initial center point of the sphere). All simulations carried out in this study are for relatively small values of the impact velocity $V_{i}$. High forward velocity of body requires a large fluid domain - invoking large computational costs - however the present formulation of the problem can be easily extended for higher impact velocities with corresponding larger computational domains.

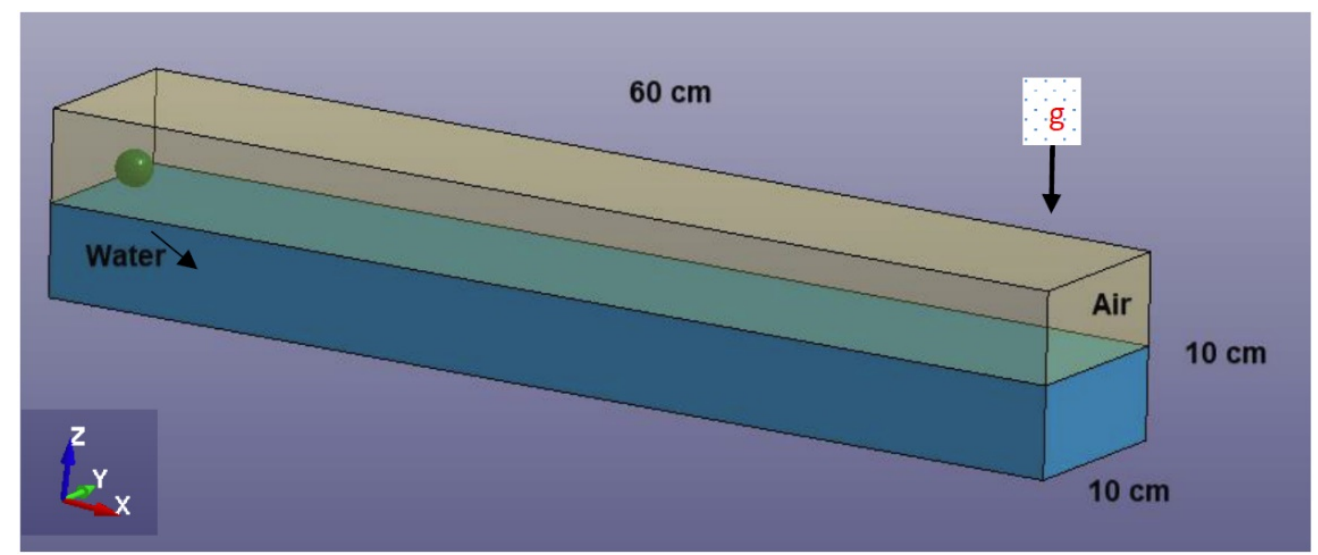

Figure 2. Three-dimensional problem geometry considered where $\theta_{i}$ the impact angle is measured with respect to the horizontal $x$-axis).

In the present study, 3-D time-dependent numerical simulations were performed by using a general-purpose finite element program LS-DYNA (14) - capable of simulating complex real world problems. The origins of the code lie in highly nonlinear, transient dynamic finite 
element analysis using explicit time integration. In this paper, three different materials (steel, titanium and duralumin) are considered for the sphere with varying impact velocities and impact angles $(\theta)$. The non-ricochet event is identified when the sphere does not come up to the air-water interface after the impact (see Figure 2).

\section{PAST ANALYTICAL MODELING OF RICOCHET}

\subsection{Ricochet from a solid surface}

A model to predict the ricochet of rod penetrators in a solid substrate was developed earlier by Segletes (15-17). The model is based on the premise that the phenomenology of ricochet is one where the impacting rod feeds into a plastic hinge located at the rod/target interface and is thus diverted from a penetrating trajectory. A ricochet event (based on the modeling methodology employed) is the one in which the projectile, during the process, axially feeds into a bend (the plastic hinge) that is stationary in the target's frame of reference and exits the hinge with its velocity redirected. During the course of the ricochet, one 'complete' side of the rod (the projectile), over the course of time, would experience intimate contact with the target. A rebound, in contrast, is an event in which the tip of the rod is primarily squashed and/or buckled, prior to rebound. In the case of rebound, one might expect to find parts of the side of the rod which never come into intimate contact with the target.

A numerical study on projectiles ricocheting off a steel plate was recently investigated (18). The numerical package LS-DYNA was used to model the process of the impact of projectile on a steel plate. The simulations were carried out for a given range of projectile velocity $(250 \mathrm{~m} / \mathrm{s}$ to $1500 \mathrm{~m} / \mathrm{s})$ with varying impact angles. From the numerical results the ricochet angle and the ricochet velocity are predicted in terms of the incident angle and the incident velocity. The impact velocity effect on the ricochet phenomenon was studied. The numerical results were compared with available analytical solutions of the ricochet problem available in the literature.

\subsection{Ricochet from a gas/liquid interface}

Based on photographic studies for projectiles impinging on a liquid surface, Richardson (3) described four types of trajectory that occur as the entry angle of the projectile is increased from zero The four types of trajectories were reported as

(a) definite ricochet

(b) break surface followed by re-entry

(c) flattening out and continuing on a straight path and

(d) continuing straight ahead, then diving.

It has been shown (4) that a modified form of the theory due to (2) provides reasonable agreement with the results of certain experimental tests described by (3):

$$
\theta_{c r} \approx(18.0 / \sqrt{\sigma})^{o}
$$

where $\theta_{c r}$ is the critical angle of impact for ricochet, beyond a critical speed and $\sigma$ is the specific gravity of the projectile material. This surprisingly simple relation neglects the effect 
of weight (or the volume or radius $\mathrm{r}$ ) of the sphere on the prediction of $\theta_{c r}$. While equation (1) implies that the critical impact angle $\theta_{c r}$ is independent of the speed of entry (an asymptotic limit for high impact velocities), there is in fact a strong impact velocity or Froude number dependency $\left(F r=V_{i}^{2} / r g\right.$ where $V_{i}$ is the impact speed and ' $r$ ' is the radius of the impinging solid sphere) on $\theta_{c r}$, particularly for lower entry speeds (4). As stated earlier, the above relation (Eq. 1) also does not include the effect of the sphere diameter. In general, $\theta_{c r}$ increases as the Froude number, Fr increases. A more complete theory for the critical impact angle must include the dependency on both the Fr and specific gravity $\sigma$ of the projectile material.

The theory by Richardson (3) is based upon certain arbitrary assumptions regarding the pressure distribution over the wetted surface, the consequences of which is that there are limitations on the results. By grouping the experimental studies (3), the critical angle for ricochet of impinging steel $(\sigma=7.8)$ spheres (having a Fr range of 2475 to 18,448 ) is given to be $6^{\circ}$, for striking velocities beyond the critical impact velocity $V_{i, c}$. The critical angle for ricochet of impinging duralumin $(\sigma=2.7)$ spheres (having a Fr range of 645 to 664) is given to be $9^{\circ}$, for striking velocities beyond the critical impact velocity $V_{i, c}$, and the critical angle for ricochet of impinging ebonite ( $\sigma=1.1$ ) spheres (having a Fr range of 697 to 894) is given to be $15^{\circ}$, for striking velocities beyond the critical impact velocity $V_{i, c}$. It should be noted here that ricochet angle becomes independent of the impact velocity only if $V_{i}>V_{i, c}$.

Experimental results are reported by (1) for the ricochet of steel and duralumin spheres from shallow depths of water and sand. The critical angle for ricochet (i.e. $\theta_{c r}$ ) off water is empirically shown (4) to increase with speed to approach the theoretical limit of

$$
\theta_{c r} \approx(17.5 / \sqrt{\sigma})^{o}
$$

at high Fr. This result again has the limitation that $\theta_{c r}$ is predicted to be independent of the sphere impact velocity (Froude number Fr). The theory indicates that $\theta_{c r}$ is inversely proportional to the square root of $\sigma$ - in agreement with De Jonquires' classical result (19). For ricochet off sand (not addressed in the present study), the critical angle decreases with speed, but a cutoff angle exists $(82 \sqrt{\sigma})^{o}$, for which no ricochet occurs at any speed.

From equation (2) the asymptotic value of the critical angle for steel $(\sigma=7.8)$ is given as $\theta_{c r} \approx(17.5 / \sqrt{7.8})^{o}=6.26^{\circ}(2)$. The corresponding asymptotic values of the critical angle for titanium $(\sigma=4.5)$ and duralumin $(\sigma=2.7)$ spheres $(\mathrm{d}=2.54 \mathrm{~cm})$ are $8.24^{\circ}$ and $10.65^{\circ}$ respectively. The asymptotic (critical) impact velocities will in general follow:

$$
\mathrm{V}_{\text {steel }_{\mathrm{i}, \mathrm{c}}}>\mathrm{V}_{\text {titanium }_{\mathrm{cr}}}>\mathrm{V}_{\text {duralumin }_{\mathrm{i}, \mathrm{c}}} \text { as } \sigma_{\text {steel }}>\sigma_{\text {titanium }}>\sigma_{\text {duralumin }}
$$

Recently DeVuyst et al. (20) investigated the ricochet behavior of a 2D cylinder impacting a water surface. The results were obtained by the SPH (Smoothed-particle Hydrodynamics) and the ALE (Arbitrary Lagrangian-Eulerian) methods in the LS-DYNA code (14). In contrast to the experimental results (3D), these results demonstrated that both the SPH and ALE models showed an over prediction of ricochet at higher impact velocities, but the SPH and ALE models agree in their over predictions. 


\section{MATHEMATICAL MODEL OF IMPACT SIMULATION ON AN AIR-WATER INTERFACE}

\subsection{Arbitrary Lagrangian Eulerian (ALE) Method}

The model geometry considered in the present study consists of three parts: water; air and the impacting solid (the sphere). The multi-media arbitrary Lagrangian-Eulerian (MM-ALE) method with fluid structure interaction (FSI) capabilities in the LS-DYNA $(14,21)$ code are employed to obtain the present solutions. The ALE is a finite element formulation in which the computational system is not a priori fixed in space (e.g. Eulerian-based finite element formulations) or attached to material (e.g. Lagrangian-based finite element formulations). ALE-based finite element simulations can alleviate many of the drawbacks that the traditional Lagrangian-based and Eulerian-based finite element simulations have. When using the ALE technique in engineering simulations, the computational mesh inside the domains can move arbitrarily to optimize the shapes of elements, while the mesh on the boundaries and interfaces of the domains can move along with materials to precisely track the boundaries and interfaces of a multi-material system. ALE-based finite element formulations can reduce to either Lagrangian-based finite element formulations by equating mesh motion to material motion or Eulerian-based finite element formulations by fixing mesh in space. ALE formulations are particularly useful for fluid-structure interaction (combination of pure Eulerian mesh, pure Lagrangian mesh and ALE mesh in different regions). Lagrangian method: mesh deforms along with the material.

The ALE formulation employs algorithms that perform automatic mesh rezoning. An ALE formulation consists of a Lagrangian, where a rigid mesh moves (the sphere in this case), time step followed by an "advection" step which remaps the Eulerian, fluid, mesh. Most ALE implementations are simplified ALE formulations which permit only a single material in each element of the mesh. The primary advantage of a simplified formulation is its reduced cost per time step. However, cases with elements having more than one material are permitted (like the simulations carried out in this paper).

For the simulations, the present model developed uses the multi material-ALE model which represent elements with more than one material by their respective volume fraction, thus the composite stress for an element in an ALE formulation is found by

$$
\tau^{*}=\sum_{k=1}^{n} \eta_{k} \tau_{k}
$$

where $\tau^{*}$ is the composite stress of an element $\mathrm{k}, \mathrm{n}$ is the number of materials in a given element, with $\eta_{k}$ and $\tau_{k}$ being the volume fraction and the stress of each material in that element, respectively.

Two main methods are used for advection, the donor cell and the Van Leer method. In this model the Van Leer method is chosen to calculate the transport of element centered variables (i.e. density, internal energy, stress tensor) because of its second order accuracy. 


\subsection{FSI Coupling}

Fluid-structure interaction (FSI) is the interaction of some movable or deformable structure (the rigid sphere in the present paper) with an internal or surrounding fluid flow. Fluidstructure interactions can be stable or oscillatory. In oscillatory interactions, the strain induced in the solid structure causes it to move such that the source of strain is reduced, and the structure returns to its former state only for the process to repeat. The fluid structure interactions are modeled by using a penalty method which places a spring normal to the interacting nodes (i.e. Lagrangian nodes, the slave nodes coming in contact with Eulerian nodes, the master nodes). When the salve node penetrates the surface of a master node, there is a contact force applied at the interface which can be calculated by

$$
\mathrm{F}_{s}=k d
$$

where $d$ is the penetration distance and $k$ is the stiffness coefficient of the fluid which can be found by

$$
k_{i}=\frac{f_{s i} K_{i} A_{i}^{2}}{V_{i}}
$$

were the stiffness $k$ for a fluid element that contains a master segment, denoted by the subscript $i$, is given in terms of the bulk modulus $K_{i}$ the face area of the segment $A_{i}$ and the volume of the element $V_{i}$, while $f_{s i}$ is a scale factor for interface stiffness and it is taken as 0.1 by default.

\subsection{Equations of Motion}

The present solver considers the following equation of motion

$$
m \boldsymbol{a}+c \boldsymbol{v}+f_{\text {int }}=f_{\text {ext }}
$$

where $\mathrm{m}$ and $\mathrm{c}$ are the mass, and damping factor; $\boldsymbol{a}$, and $\boldsymbol{v}$ are the acceleration, and velocity vectors respectively; with $f_{\text {ext }}$ and $f_{\text {int }}$ being the external and internal forces, respectively.

This equation of motion is solved using the initial inputs (at $t=0)$ and the values are updated after subsequent time intervals. The acceleration, velocity and displacement are updated using the central difference method, where the velocity is calculated from

$$
\mathrm{v}^{n+\frac{1}{2}}=v^{n-\frac{1}{2}}+\mathrm{a}^{n} \Delta t^{n}
$$

where $\mathrm{v}$ is the velocity, $\Delta t$ is the time step, and $\mathrm{n}$ is the time state, $\Delta t^{n+\frac{1}{2}}$ is found from

$$
\Delta t^{n+\frac{1}{2}}=\frac{\left(\Delta t^{n}+\Delta t^{n+1}\right)}{2}
$$

and the displacement is found from

$$
u^{n+1}=u^{n}+v^{n+\frac{1}{2}} \Delta t^{n+\frac{1}{2}}
$$


where $\mathrm{u}$ is the displacement. The internal forces are found by

$$
f_{\text {int }}^{n+1}=\int_{V} B^{T} \zeta^{n+1} d V
$$

where $V$ is the volume (in this case it is the volume of the element), $\zeta$ is the stress on the element and it is updated along with the strain $\varepsilon$ from the constitutive relations of the material, and $B^{T}$ is the transpose matrix of the strain displacement matrix $B$ given as:

$$
B=\left(\begin{array}{ccc}
\frac{\partial}{\partial x} & 0 & 0 \\
0 & \frac{\partial}{\partial y} & 0 \\
0 & 0 & \frac{\partial}{\partial z} \\
\frac{\partial}{\partial y} & \frac{\partial}{\partial x} & 0 \\
0 & \frac{\partial}{\partial z} & \frac{\partial}{\partial y} \\
\frac{\partial}{\partial z} & 0 & \frac{\partial}{\partial x}
\end{array}\right)
$$

And in the transposed form:

$$
B^{T}=\left(\begin{array}{cccccc}
\frac{\partial}{\partial x} & 0 & 0 & \frac{\partial}{\partial y} & 0 & \frac{\partial}{\partial z} \\
0 & \frac{\partial}{\partial y} & 0 & \frac{\partial}{\partial x} & \frac{\partial}{\partial z} & 0 \\
0 & 0 & \frac{\partial}{\partial z} & 0 & \frac{\partial}{\partial y} & \frac{\partial}{\partial x}
\end{array}\right)
$$

Finally, the external forces are computed from body loads and material properties specified by the user. The acceleration is then updated from

$$
a^{n+1}=M^{-1}\left(P^{n+1}-F^{n+1}-H^{n+1}\right)
$$

where $M$ is the diagonal mass matrix, $\mathrm{P}$ is the body forces (external and internal including acceleration due to gravity $\mathrm{g}$ ), $\mathrm{F}$ is the stress divergence vector which includes nonlinearities and inelastic material behavior, and $\mathrm{H}$ is the hourglass resistance (22) - a spurious deformation mode, which is usually neglected. After the acceleration, velocity, and displacement are updated the same calculations are repeated. 


\subsection{Equations of State}

The air is modeled as an ideal gas using a linear polynomial equation of state. The ratio of specific heats $(\gamma)$ is set equal to 1.4 . The Grüneisen equation of state $(23,24)$ is used to model the compressible behavior of water.

\subsection{Material Models}

Material model for the sphere (steel, titanium or duralumin) was MAT20 rigid (21). The sphere motion was restricted to the $\mathrm{x}-\mathrm{z}$ plane, with constrained rotation. The load curve for gravity was defined with gravity acting in the negative $\mathrm{z}$ direction (see Figure 2).

The metal sphere is modeled using the rigid material model which is a cost-efficient way to model solid elements that do not undergo deformation, which pertains to this study. Furthermore, the fluid materials (air and water) are modeled using the Null material model which is useful because it allows the user to specify the density and viscosity of the fluids and relates these quantities to equations of states that are used to calculate the pressures at various time steps.

\subsection{Model Geometry Details}

The model here consists of three parts: water; air and the solid sphere. The sphere (having a diameter of $2.0 \mathrm{~cm}$ ) is directed into water at a given angle with a given speed. The water domain is rectangular $(60.0 \times 10.0 \times 1.0 \mathrm{~cm})$ with a uniform mesh size $2.0 \times 2.0 \times 2 \mathrm{~mm}$. The air domain is also rectangular $(60.0 \times 10.0 \times 1.0 \mathrm{~cm})$ with mesh size $2.0 \times 2.0 \times 2.0$ $\mathrm{mm}$. Only six-sided elements for ALE mesh are considered. The meshes of air and water in the plane of contact were joined together. Disjointed meshes are often due to mesh generation of sub-domains of a single part which result in free nodes along internal edges. The air and water parts are then assembled (14). A finite element model of the sphere is developed. The size of 17 the Lagrangian grid (for the sphere) is of the same order as the Eulerian meshes for the air-water domains.

Appropriate initial and boundary conditions are imposed for the numerical solution of the governing equations for the impact problem (21) shown schematically in Figure 2 earlier. At initial time ( $\mathrm{t}=0$ seconds) the rigid sphere is given an initial velocity $V_{i}$, and the air and water domains are at rest. A viscous air domain is considered along with the water domain. The quiescent air layer is considered to be at atmospheric pressure. Water boundaries with tank edges are no-slip whereas the unbounded air surfaces (four sides and the top) are considered as open (zero-gradient) boundary conditions. 


\section{RESULTS AND DISCUSSION}

Simulations were carried out for three primary sets of input data. These simulations show different impacts of the solid sphere on the air-water interface at varying impact angles and impact velocities with the goal of zeroing on the maximum incident angle (the critical ricochet angle) at varying impact speeds for the three different sphere materials. The $\left(F_{r}=V_{i}^{2} / r g\right)$ of each simulation is calculated and the range of Fr for each set of simulation is increased by varying the impact velocity $\mathrm{Vi}$ or the acceleration due to gravity $\mathrm{g}$ or both. Calculations were carried out normal gravity $\left(\mathrm{g}=9.81 \mathrm{~m} / \mathrm{s}^{2}=1.0 g_{\text {nor }}\right)$, high gravity $\left(\mathrm{g}=98.1 \mathrm{~m} / \mathrm{s}^{2}=10.0 g_{\text {nor }}\right)$, and reduced gravity $\left(\mathrm{g}=0.98 \mathrm{~m} / \mathrm{s}^{2}=0.1 g_{\text {nor }}\right)$ conditions. From $\mathrm{Fr}=V_{i}^{2} / \mathrm{rg}$, it can be seen that by increasing the $g$, smaller values of $F r$ are realized while larger values of Fr are obtained by lowering the value of $\mathrm{g}$. The range of Fr considered here is from 100 to 90000 .

The critical angle $\theta_{c r}$ for given values of Fr and $\sigma$ was found by varying the impact angle $\theta_{i}$. Table 1 summarizes the impact simulation cases considered with a sphere radius $r=1.0 \mathrm{~cm}$. The calculations were carried out for steel, copper and duralumin spheres while the superscripts $\mathrm{a}, \mathrm{b}$ and $\mathrm{c}$ for each case indicates the acceleration due to gravity value considered, $10.0 g_{\text {nor }}, 1.0 g_{\text {nor }}$, and $0.1 g_{\text {nor }}$. There are three major columns in the table which pertains to cases for a steel sphere (with $\sigma=7.8$ and a diameter of $2.0 \mathrm{~cm}$ ); a titanium sphere (with specific gravity of 4.5 and a diameter of $2.0 \mathrm{~cm}$ ); and a duralumin sphere (with specific gravity $\sigma_{\text {duralumin }}$ of 2.7 and a diameter of $2.0 \mathrm{~cm}$ ). The table shows the 'ricochet/no ricochet' outcome from the simulations, and the maximum angle of impact that generates a ricochet is termed as $\theta_{c r}$.

Table 1. Summary of the impact simulation cases considered with a sphere radius $r=1.0 \mathrm{~cm}$ (the superscripts $\mathrm{a}, \mathrm{b}$ and $\mathrm{c}$ for each case indicates the acceleration due to gravity values considered, $10.0 g_{\text {nor }}, 1.0 g_{\text {nor }}$, and $0.1 g_{\text {nor }}$ respectively.

\begin{tabular}{|c|c|c|c|c|c|c|c|c|c|}
\hline \multicolumn{4}{|c|}{$\begin{array}{r}\text { Steel } \sigma=7.8 \\
\end{array}$} & \multicolumn{3}{|c|}{ Titanium $\sigma=4.5$} & \multicolumn{3}{|c|}{ Duralumin $\sigma=2.7$} \\
\hline \multicolumn{3}{|c|}{$\begin{array}{l}\text { Froude Impact Ricochet } \\
\text { Number velocity } \mathrm{Y} / \mathrm{N} \\
F r \quad V_{i}(\mathrm{~m} / \mathrm{s}) \\
\end{array}$} & \multicolumn{3}{|c|}{$\begin{array}{l}\text { Critical Impact Ricochet } \\
\text { angle velocity } \mathrm{Y} / \mathrm{N} \\
\left(\theta_{c r}\right) \quad V_{i}(\mathrm{~m} / \mathrm{s}) \\
\end{array}$} & $\begin{array}{l}\text { Critica } \\
\text { angle } \\
\left(\theta_{c r}\right) \\
\end{array}$ & \multicolumn{2}{|c|}{$\begin{array}{l}\text { Impact Ricochet } \\
\text { velocity } \mathrm{Y} / \mathrm{N} \\
V_{i}(\mathrm{~m} / \mathrm{s})\end{array}$} & \multirow{2}{*}{$\begin{array}{l}\begin{array}{l}\text { Critical } \\
\text { angle } \\
\left(\boldsymbol{\theta}_{c r}\right)\end{array} \\
0^{\circ}\end{array}$} \\
\hline 100 & $10.0^{\mathrm{a}}$ & $\mathrm{N}$ & NA & $10.0 \mathrm{a}$ & $\mathrm{N}$ & NA & $10.0 \mathrm{a}$ & $\mathrm{N}$ & \\
\hline 225 & $15.0^{\mathrm{a}}$ & $\mathrm{N}$ & NA & $15.0 \mathrm{a}$ & $\mathrm{N}$ & NA & $15.0 \mathrm{a}$ & $\mathrm{N}$ & $0^{\circ}$ \\
\hline 256 & $16.0^{\mathrm{a}}$ & $\mathrm{N}$ & NA & $16.0 \mathrm{a}$ & $\mathrm{N}$ & NA & $5.0 \mathrm{~b}$ & $\mathrm{Y}$ & $2^{\circ}$ \\
\hline 361 & $19.0^{\mathrm{a}}$ & $\mathrm{N}$ & NA & $6.0 \mathrm{~b}$ & Y & $3^{\circ}$ & $6.0 \mathrm{~b}$ & Y & $4^{\circ}$ \\
\hline 484 & $22.0^{\mathrm{a}}$ & Y & $2^{\circ}$ & $7.0 \mathrm{~b}$ & Y & $5^{\circ}$ & $7.0 \mathrm{~b}$ & $\mathrm{Y}$ & $6^{\circ}$ \\
\hline 676 & $8.0^{\mathrm{b}}$ & Y & $3^{\circ}$ & $8.0 \mathrm{~b}$ & Y & $6^{\circ}$ & $8.0 \mathrm{~b}$ & Y & $8^{\circ}$ \\
\hline 1024 & $10.0^{\mathrm{b}}$ & Y & $4^{\circ}$ & $10.0 \mathrm{~b}$ & $\mathrm{Y}$ & $7^{\circ}$ & $10.0 \mathrm{~b}$ & Y & $9^{\circ}$ \\
\hline 2304 & $15.0^{\mathrm{b}}$ & Y & $5.25^{\circ}$ & $15.0 \mathrm{~b}$ & Y & $8^{\circ}$ & $15.0 \mathrm{~b}$ & Y & $10^{\circ}$ \\
\hline 4096 & $20.0^{\mathrm{b}}$ & Y & $5.75^{\circ}$ & $20.0 \mathrm{~b}$ & Y & $8.25^{\circ}$ & $20.0 \mathrm{~b}$ & Y & $10.25^{\circ}$ \\
\hline 10000 & $10.0^{\mathrm{c}}$ & Y & $6.25^{\circ}$ & $10.0 \mathrm{c}$ & Y & $8.5^{\circ}$ & $10.0 \mathrm{c}$ & Y & $10.5^{\circ}$ \\
\hline 40000 & $20.0^{\mathrm{c}}$ & Y & $6.25^{\circ}$ & $20.0 \mathrm{c}$ & Y & $8.5^{\circ}$ & $20.0 \mathrm{c}$ & Y & $11^{\circ}$ \\
\hline 62500 & $25.0^{\mathrm{c}}$ & Y & $6.5^{\circ}$ & $25.0 \mathrm{c}$ & Y & $8.75^{\circ}$ & $25.0 \mathrm{c}$ & Y & $11.25^{\circ}$ \\
\hline 90000 & $30.0^{\mathrm{c}}$ & $\mathrm{Y}$ & $6.5^{\circ}$ & $30.0 \mathrm{c}$ & $\mathrm{Y}$ & $8.85^{\circ}$ & $30.0 \mathrm{c}$ & $\mathrm{Y}$ & $11.5^{\circ}$ \\
\hline
\end{tabular}




\subsection{Simulations with a steel sphere}

Figure 3 below shows the instantaneous projectile (steel sphere) position and the deformed air-water interface (when the sphere is about to exit the computational domain) for various impact velocities when Fr range is between 100 and 90000. Figure 3(a) shows the case with

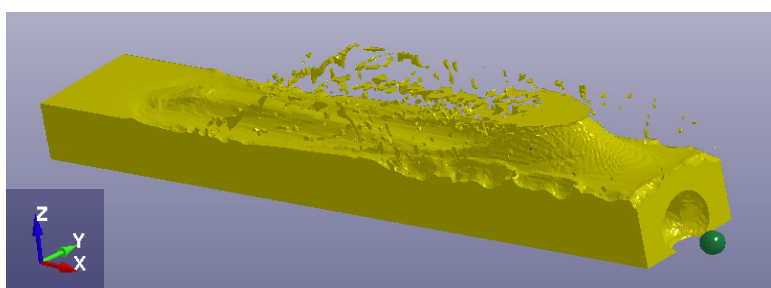

(a)

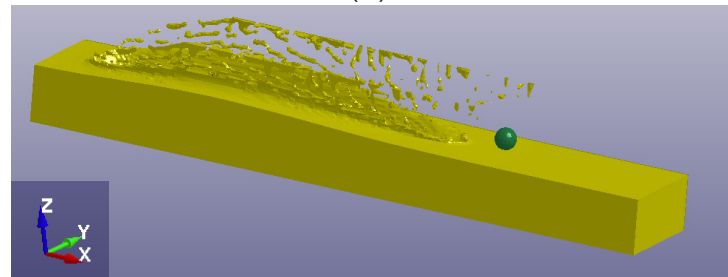

(b)

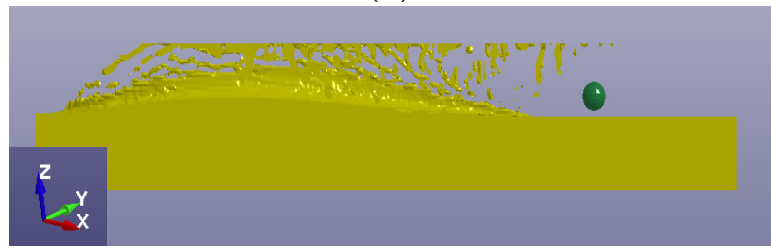

(c)

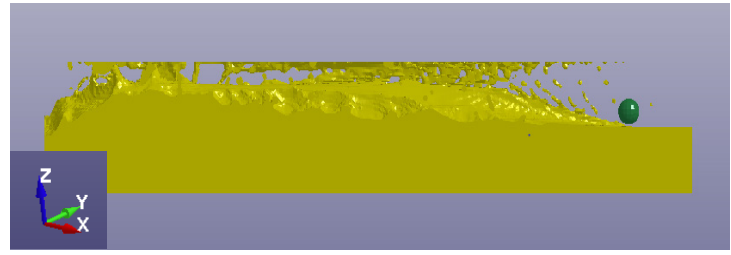

(d)

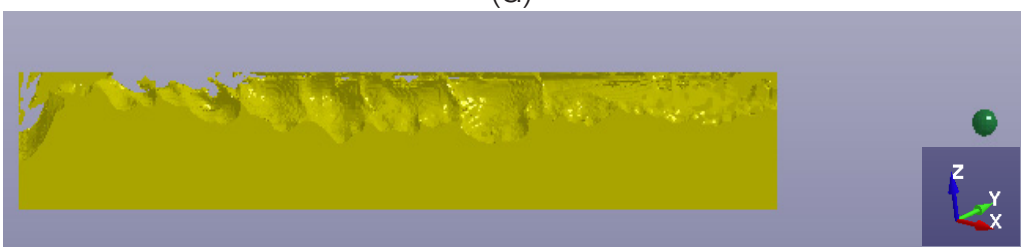

(e)

Figure 3. Deformed air-water interface with the steel sphere exiting the computational domain (a) $\mathrm{Fr}=225$ at $\mathrm{g}=10 . \mathrm{Og}_{\text {nor }}(\mathrm{V}=15 \mathrm{~m} / \mathrm{s})$ and $\left.\theta=0.5^{\circ}\right)$; (b) $\mathrm{Fr}=676$ at $\mathrm{g}=1 . \operatorname{Og}_{\text {nor }}(\mathrm{V}=8 \mathrm{~m} / \mathrm{s})$ and $\left.\theta=3^{\circ}\right)$; (c) $\mathrm{Fr}=1024$ at $\mathrm{g}=1 . \lg _{\text {nor }}(\mathrm{V}=10 \mathrm{~m} / \mathrm{s})$ and $\theta=4^{\circ} ;(\mathrm{d}) \mathrm{Fr}=62500$ at $\mathrm{g}=0.1 \mathrm{~g}$ nor $(\mathrm{V}=25 \mathrm{~m} / \mathrm{s})$ and $\theta=6.5^{\circ}$; and $(\mathrm{e}) \mathrm{Fr}=90000$ at $\mathrm{g}=0.1 \mathrm{~g}_{\text {nor }}(\mathrm{V}=30 \mathrm{~m} / \mathrm{s})$ and $\theta=6.5^{\circ}$ 
no ricochet. Ricochet of the sphere is observed for the cases shown in Figures 3(b) - 3(d). For Figure 3(e), where $\mathrm{Fr}=90000$ at $\mathrm{g}=0.1$ gnor $(\mathrm{V}=30 \mathrm{~m} / \mathrm{s})$ and $\theta=6.5^{\circ}$ shows that the ricochet occurs after the sphere travels a longer path than in the previous cases.

The results show that the critical angle $\theta_{c r}$ is Fr dependent and attains an asymptotic value $\left(\sim 6.5^{0}\right)$ at high $\mathrm{Fr}$. The sphere did not ricochet in regions where Fr falls below 360 . Similarly, the critical angles were determined at high Fr ranges by simulations where the impact angles were varied systematically. It was shown that at high $\operatorname{Fr}(>10000)$, the critical impact angle is less than $7^{\circ}$.

Figure 4(a) shows the theoretical results and experimental measurements by (1) for the critical impact angle as a function of the impact velocity $V_{i}$ for a steel sphere $(\sigma=7.8, \mathrm{~d}=$ $2.54 \mathrm{~cm}$ ) impacting an air-water interface. Considerable disagreements are present between the experimental measurements and the theoretical predictions, particularly in the intermediate range of the impact velocities considered (1). Any point on the plane lying above the theoretical or experimental lines indicate lack of ricochet (theoretically and experimentally). The areas under the curves (experimental and theoretical) show the conditions necessary for ricochet behavior. The Fr ranges between zero to 46000 for the results shown in Figure 4(a) and the critical angle is independent of the impact velocity of $75.0 \mathrm{~m} / \mathrm{s}$ or higher for a corresponding $>45150$. For higher impact velocities (approximately $V_{\text {steel }_{\text {critical }}}>75.9 \mathrm{~m} / \mathrm{s}$ ), the experimental data indicate that the critical angle becomes independent of the impact velocity and approaches the value of about $6.3 \mathrm{o}$, close to the theoretical prediction of $\theta_{c} \approx(17.5 / \sqrt{7.8})^{o}=6.26^{\circ}$ given in $(2)$.

Figure 4(b) shows results from the present simulations along with the experimental and theoretical data obtained by (1). However, the impact velocities are converted into Froude numbers due to difference in the diameter of the projectile in (1) with the one used in the present simulations $(2.54 \mathrm{~cm}$ and $2.0 \mathrm{~cm}$, respectively).

Figure 4(b) shows that the current simulation results lie in between the theoretical and the experimental results from (1), with the notion that the current results are closer to the experimental results than those predicted by the theoretical model. Again at large Fr of 42000, the critical angle is about 6.25o which is close to the angles shown in figure 4(b) at similar Fr. The simulation results show that at the very high Fr of 90000 , the critical angle is shown to be around 6.50 which is close to the theoretical angle limit of 6.260 predicted by (2).

\subsection{Simulations with a titanium sphere}

Figure 5 below shows the instantaneous projectile (a titanium sphere) position and the deformed air-water interface (when the sphere is about to exit the computational domain) with varying impact velocities. The corresponding critical angles are shown earlier in Table 1. Titanium specific gravity is low compared to that of the heavier metal (steel, $\sigma=7.8$ ) which affects the corresponding asymptotic value of the critical impact angle. The theoretical limit, of the critical angle for the titanium sphere is about $8.24^{\circ}$ (for high Fr cases)(2).

Figure 5(a) and 5(b) show cases where no ricochet occurred, while figure 5 (a) shows an immediate sink while figure $5(\mathrm{~b})$ shows the projectile travelling along the path before emerging at the end of the computational domain. Figures 5(c) - (e) show cases where ricochet is observed. Similar to the steel cases, no ricochet events were observed for low Fr (approximately $\mathrm{Fr}<360$ ). At high $\mathrm{Fr}$, the critical angle was found to be close to $8.85^{\circ}$ which is close to that predicted by (2).No experimental data for the ricochet behavior of titanium sphere could be found. 


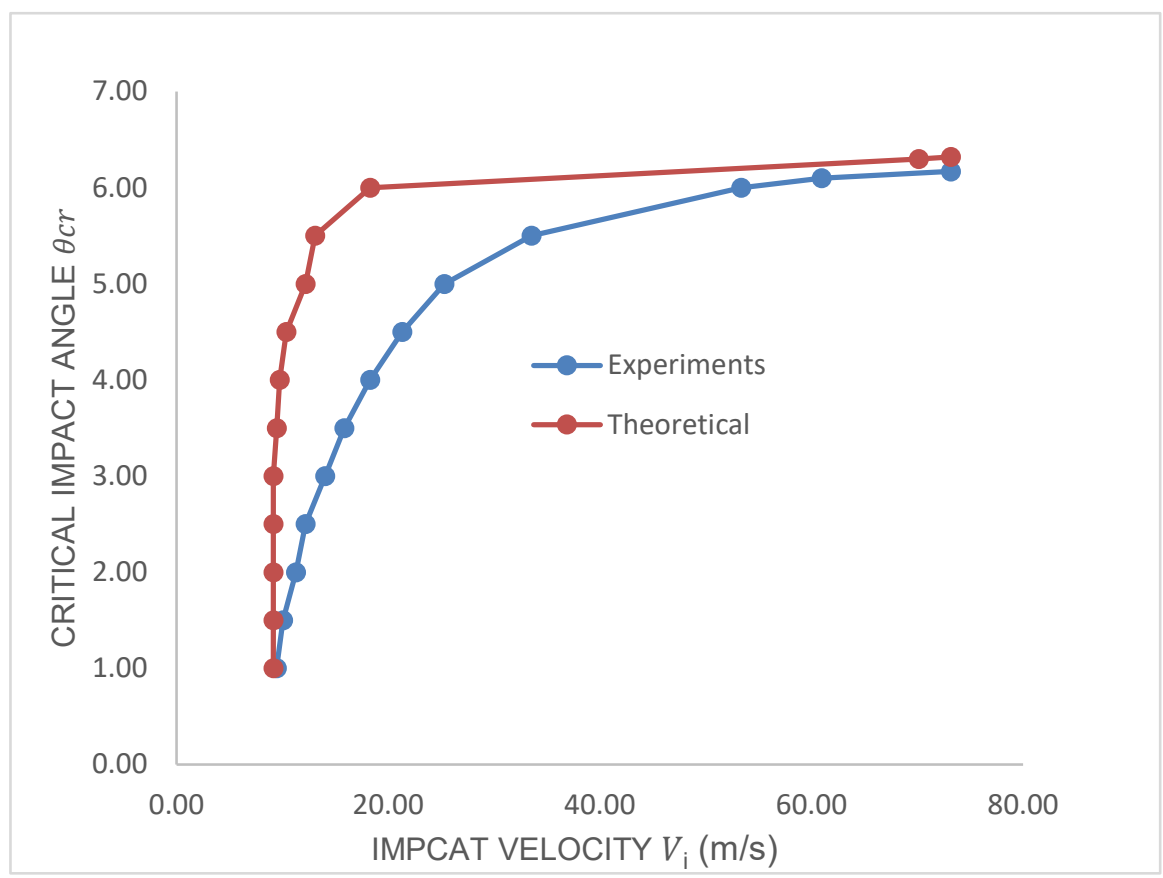

(a)

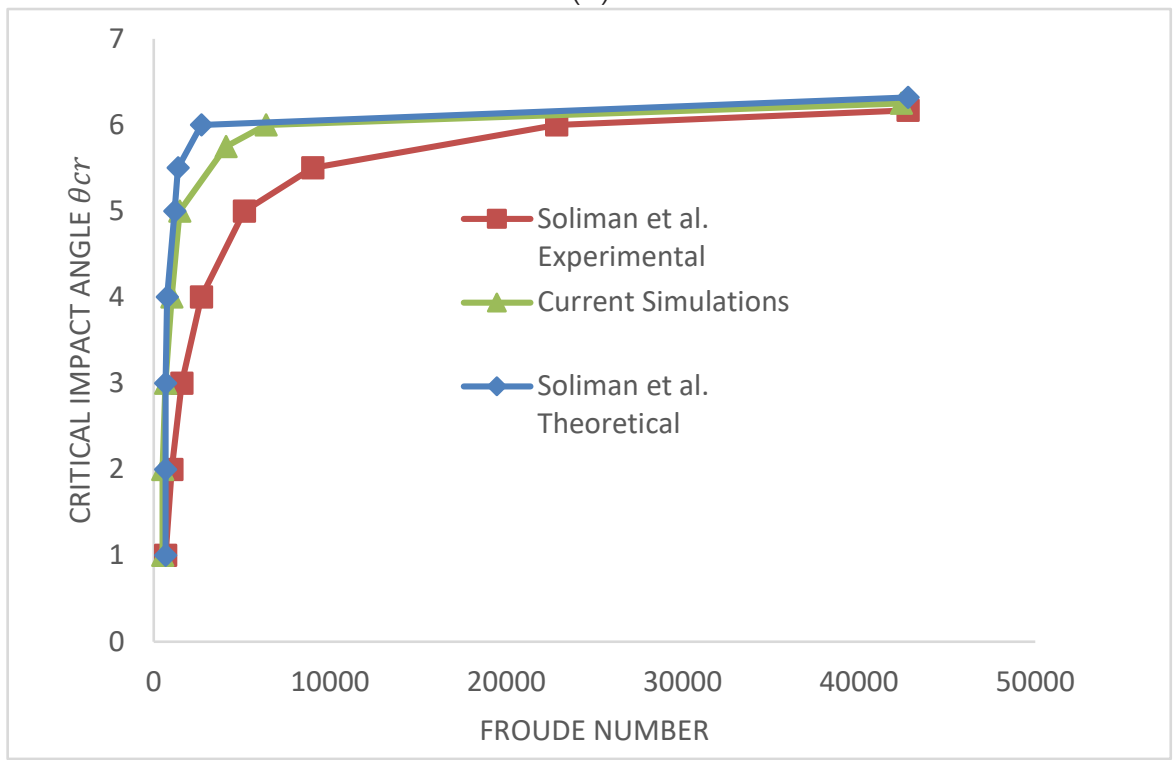

(b)

Figure 4. (a) Experimental data and theoretical predictions of the critical impact angle (1) as a function of the impact velocity for a steel $(\sigma=7.8)$ sphere $(d=2.54$ $\mathrm{cm}$ )with varying impact velocity from 0.0 to $75.0 \mathrm{~m} / \mathrm{s}$. (b) Comparison of the present simulation results with results from (1) for critical impact angle $\theta_{c r}$ as a function of the $\mathrm{Fr}$ 


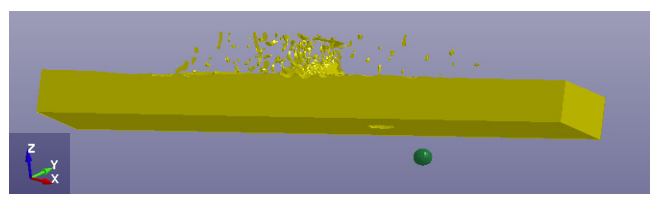

(a)

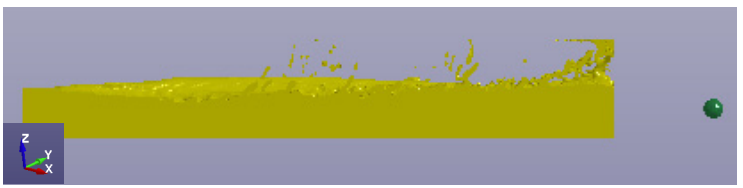

(b)

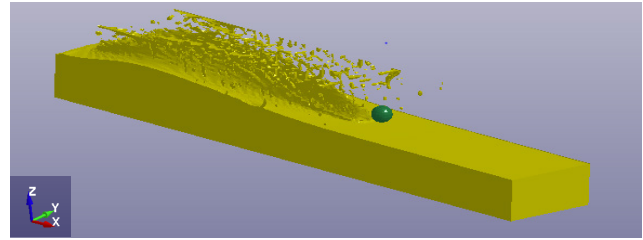

(c)

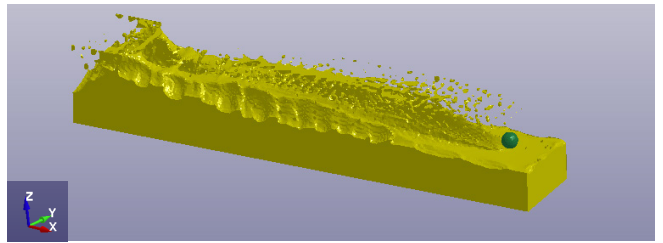

(d)

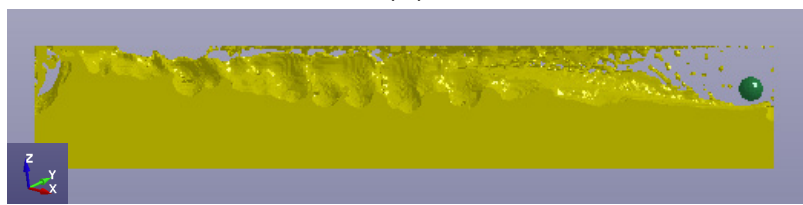

(e)

Figure 5. Deformed air-water interface with the titanium sphere exiting the computational domain (a) $\mathrm{Fr}=100$ at $\mathrm{g}=10 . \lg _{\text {nor }}(\mathrm{V}=10 \mathrm{~m} / \mathrm{s}), \theta=1^{\circ}$; (b) $\mathrm{Fr}=225$ at $g=10 . \lg _{\text {nor }}(V=15.0 \mathrm{~m} / \mathrm{s}), \theta=2^{\circ}$; (c) $\mathrm{Fr}=1024$ at $g=1.0 \operatorname{lgg}_{\text {nor }}(\mathrm{V}=10 \mathrm{~m} / \mathrm{s}), \theta=7^{\circ}$; (d) $\mathrm{Fr}=2304$ at $\mathrm{g}=1 . \log _{\text {nor }}(\mathrm{V}=15 \mathrm{~m} / \mathrm{s}), \theta=8^{\circ}$; and $(e) \mathrm{Fr}=62500$ at $\mathrm{g}=0.1 \mathrm{~g}_{\text {nor }}(\mathrm{V}=25$ $\mathrm{m} / \mathrm{s}), \theta=8.75^{\circ}$.

\subsection{Simulations with a duralumin sphere}

Figure 6 below shows the instantaneous projectile (a duralumin sphere, $\sigma=2.7$ ) position and the deformed air-water interface (when the sphere is about to exit the computational domain) with varying impact velocities. Due to its low specific gravity, the corresponding asymptotic values of the critical impact angle from Equation (1) for the duralumin sphere is about $10.65^{\circ}$ for high $\operatorname{Fr}(2)$.

Figure 6(a) shows a case where there is no ricochet, while cases 6(b) - (d) show cases where ricochet was observed. The duralumin sphere shows no ricochet at low $\mathrm{Fr}$ (for $\mathrm{Fr}<250$ ). However, the general trend seen here is that as the specific gravity is decreasing, i.e. lighter 
material is tested, the ricochet event occurs at lower Fr which intuitively makes sense. For the duralumin spheres, the critical angle at high Fr was observed to be around $11.5^{\circ}$ which is about 10 degree higher than the theoretical asymptotic critical angle from equation (1).

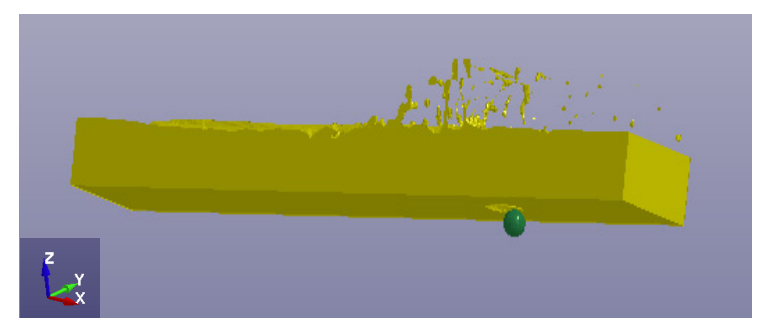

(a)

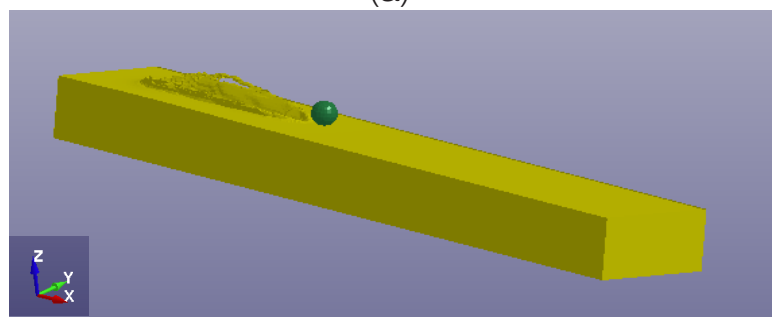

(b)

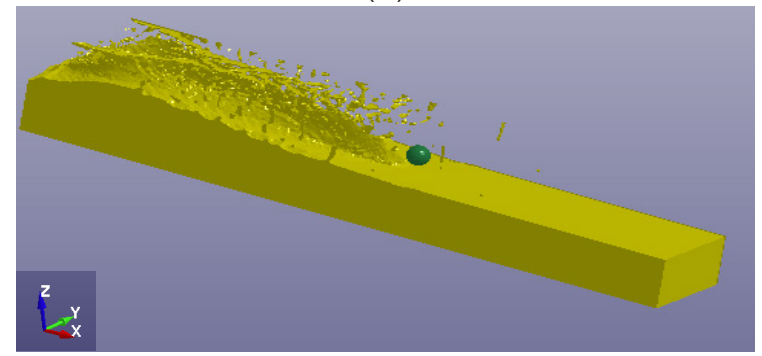

(c)

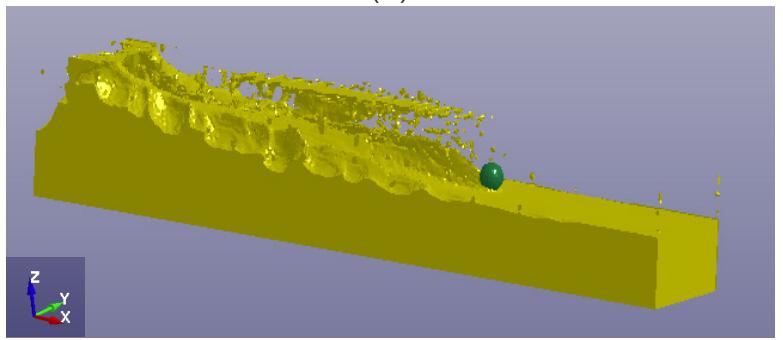

(d)

Figure 6. Deformed air-water interface with the duralumin sphere exiting the computational domain (a) $\mathrm{Fr}=100$ at $\mathrm{g}=10 . \mathrm{Og}_{\text {nor }}(\mathrm{V}=10 \mathrm{~m} / \mathrm{s}), \theta=0.5^{\circ}$; (b) $\mathrm{Fr}=256$ at $g=1.0 g_{\text {nor }}(V=5.0 \mathrm{~m} / \mathrm{s}), \theta=2^{\circ}$; (c) $\mathrm{Fr}=2304$ at $g=1.0 g_{\text {nor }}(\mathrm{V}=15 \mathrm{~m} / \mathrm{s}), \theta=10^{\circ}$; (d) $\mathrm{Fr}=40000$ at $\mathrm{g}=0.1 \mathrm{~g}_{\text {nor }}(\mathrm{V}=20 \mathrm{~m} / \mathrm{s}), \theta=11^{\circ}$ 


\subsection{Comparative analysis}

The results shown in Table 1 earlier are plotted in Figure 7 below which shows the critical angle variation against the Fr range from 0 to 90000 for the three materials (steel, titanium and duralumin) considered.

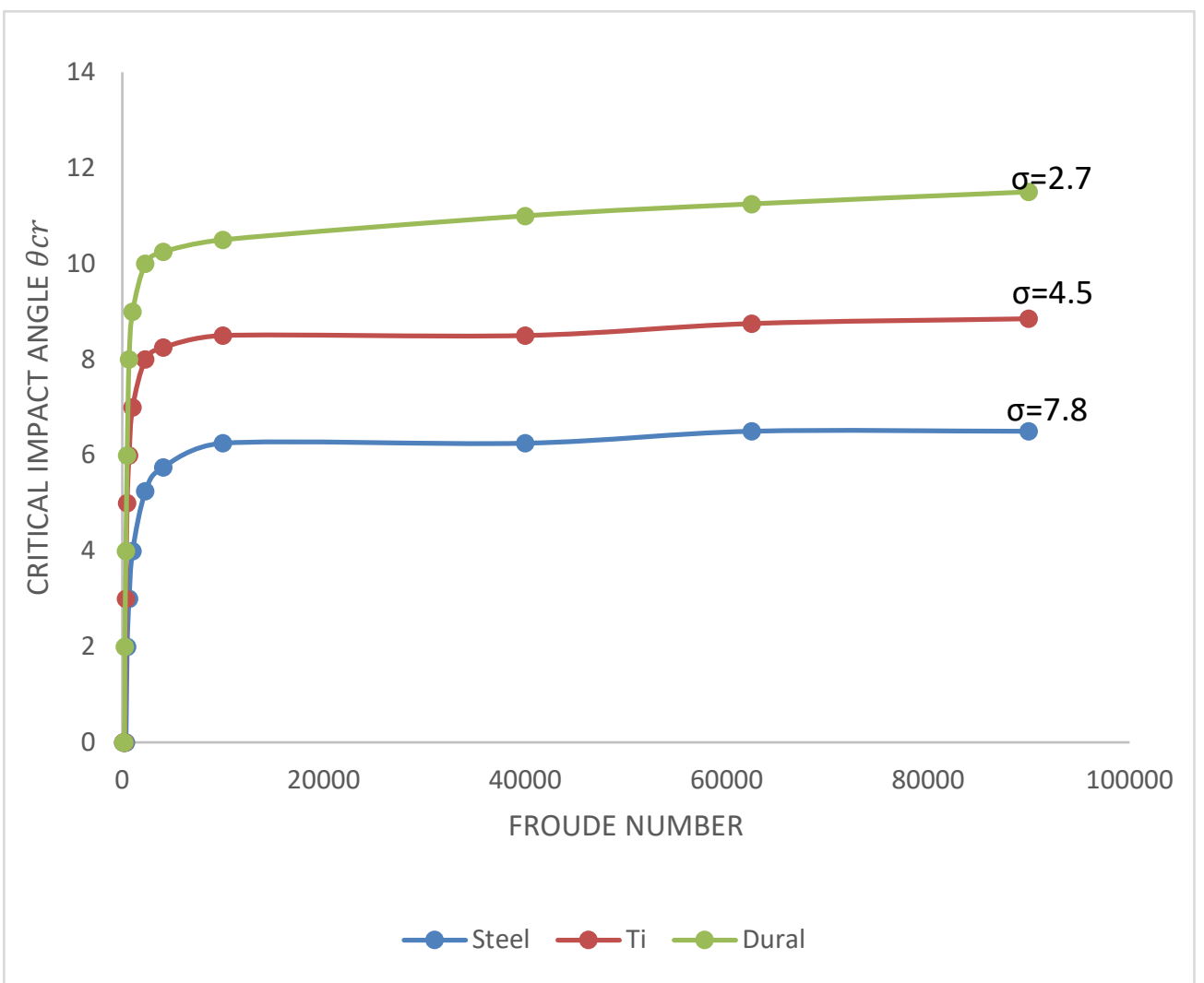

Figure 7. Variation of critical angle observed from the simulation vs. the Fr for steel $(\sigma=7.8)$, titanium $(\sigma=4.5)$, and duralumin $(\sigma=2.7)$ spheres

From Figure 7, the three curves show close similarity with the error function profile as approximated by the function $\theta_{c r}=f[\operatorname{erf}(F r)]$ where the error function $\operatorname{erf}(F r)$ is defined as

$$
\operatorname{erf}(F r)=\frac{2}{\sqrt{\pi}} \int_{0}^{F r} e^{-t^{2}} d t
$$

In order to include the dependency of both Fr and the specific gravity $\sigma$ of the sphere on $\theta_{c r}$ we propose a correlation in the following form

$$
\theta_{c r}=a \cdot \operatorname{erf}\left(F r^{b}\right)+c \cdot \sigma-d
$$


where $a, b, c$ and $d$ are the coefficients to be determined via a fitting method employing the data shown earlier in Table 1.

The coefficients in the proposed equation (13) are obtained via a standard 'least square fit' method. The following final form of equation (14) is obtained by employing the data set earlier presented in Table 1:

$$
\left.\theta_{c r}=252.632 \cdot \operatorname{erf}\left(F r^{0.086}\right)-0.89936\right) \cdot \sigma-239.2
$$

Figure 8 below shows the deviation of the proposed equation from the simulation results. The symbols in the figure represents the numerically predicted critical angle values while the diagonal line represents the correlation given by equation (14). The fit of the numerical data to the proposed correlation is very good. The $\mathrm{Fr}$ range used to achieve this fit was between 480 to 90000 . Below this range the critical angles predicted are limited or close to the theoretical asymptotic angle predicted from equation (1).

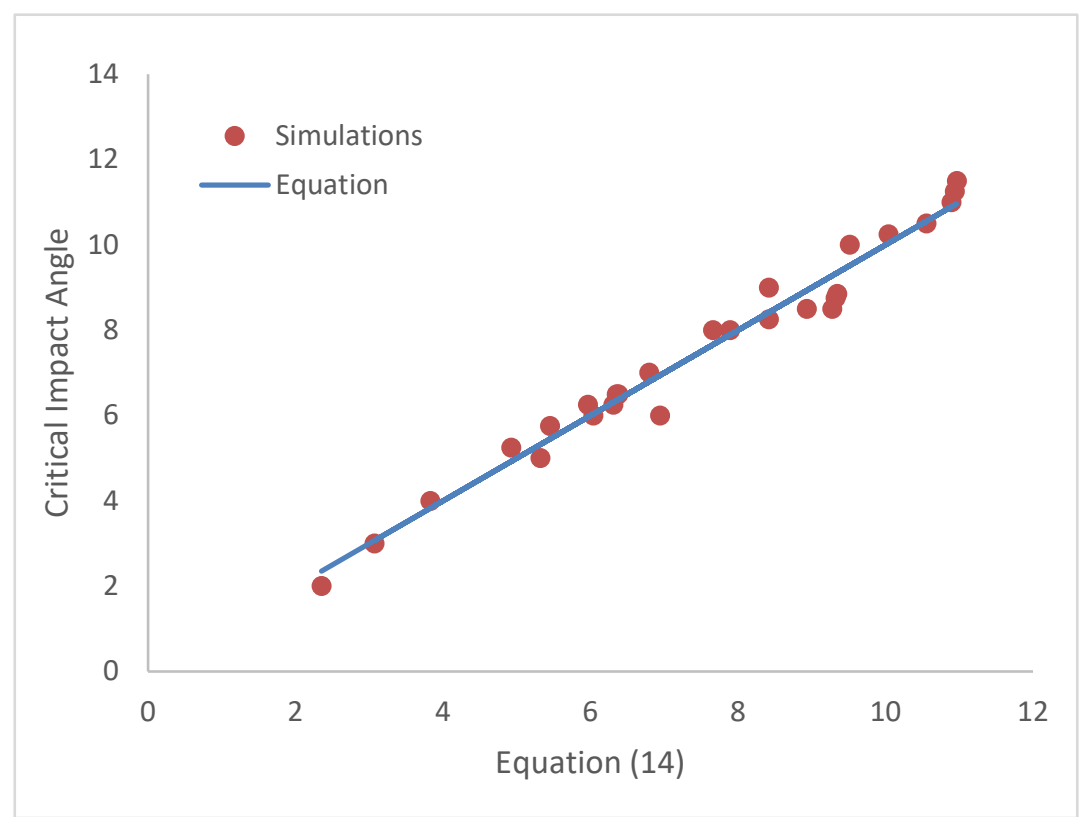

Figure 8. Data fit between predicted critical angle from equation (14) and predicted critical angles from the simulation.

The error in the fitting is defined as the squared sum of the difference between the observed critical angle from the simulation $\theta_{\operatorname{cr}(\text { Simulation) }}$, and the critical angle predicted from the above equation (16).

$$
\text { err }=\sum\left(\theta_{\text {cr(simulation })}-\theta_{\text {cr(equation 14) }}\right)^{2}
$$


The mean absolute percentage error (MAPE) given below is the average of the relative percentage errors which are the absolute difference between the observed critical angle from the simulation, $\theta_{\operatorname{cr}(\text { Simulation) }}$ and the critical angle predicted from equation (16).

$$
M A P E=\frac{1}{n} \sum_{i=1}^{n}\left|\frac{\theta_{c r(\text { simulation })}-\theta_{c r(\text { equation } 14)}}{\theta_{c r(\text { simulation })}}\right|
$$

From the present simulations the mean absolute percentage error is found to be $4.72 \%$ indicating a good fit of the data to the proposed correlate, equation (16).

Three different arbitrary simulation runs were performed to test equation (16) using each sphere material. The Froude number was in the range of 3000 - 7000. The steel sphere was tested for a Froude number of 3000 (at normal gravity and at speed $17 \mathrm{~m} / \mathrm{s}$ ) and the critical angle was found to be around 5.5, and the model, equation (16), predicted the critical angle to be at 5.18. Likewise, the titanium sphere was tested for $\mathrm{Fr}=7000$ (at normal gravity and at speed $26 \mathrm{~m} / \mathrm{s}$ ) the critical angle was found to be around 8.5 and the model predicted 8.76. Finally, the duralumin sphere was tested for $\mathrm{Fr}=5000$ (at normal gravity and at speed $22 \mathrm{~m} / \mathrm{s}$ ) the critical angle was around 11 while the model predicted 10.18. Figure 9 shows how the arbitrary simulation runs agree with equation (16). The steel and titanium results agree better with the model that the result from duralumin. This happens to be the general trend seen from the duralumin results in section 5.3, where the asymptotic critical angle was underestimated by equation (1).

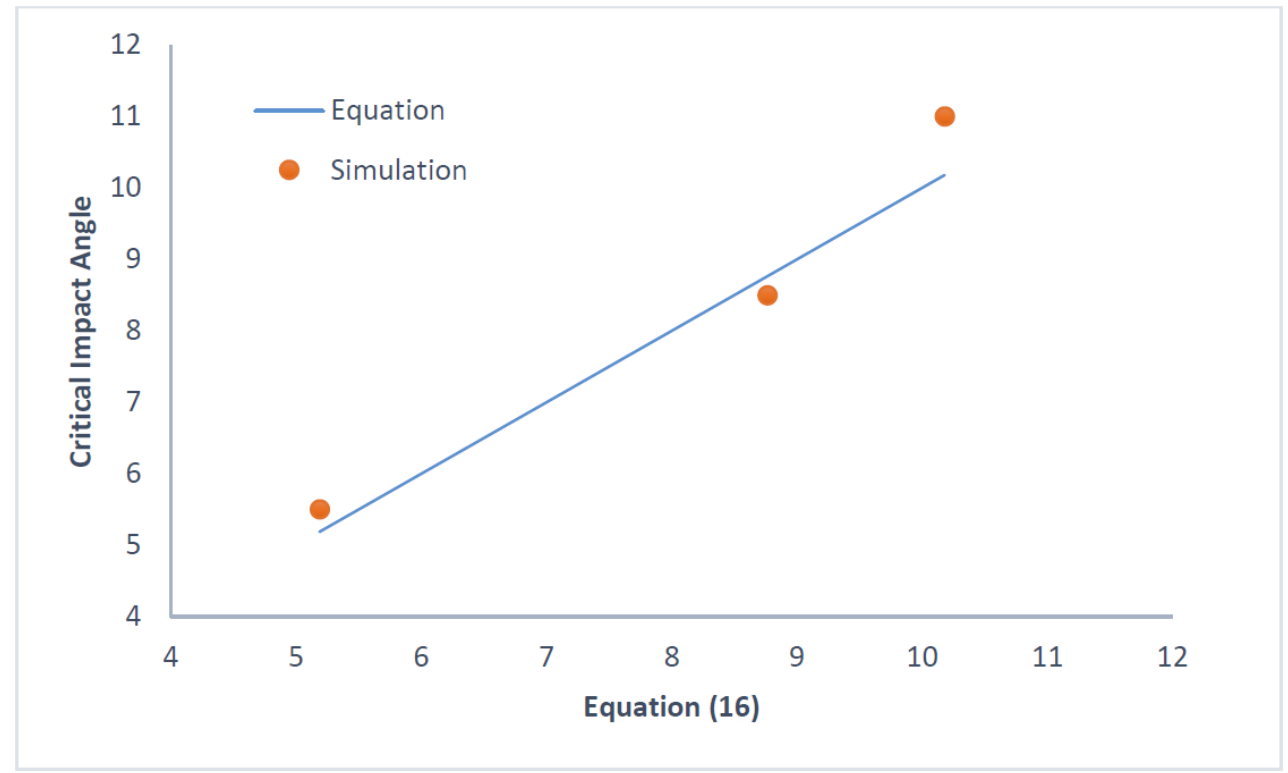

Figure 9. Data fit between predicted critical angle from equation (16) and from additional cases not used in the development of equation (16) 


\section{CONCLUSIONS}

Ricochet of a solid projectile from an air-water interface is a challenging and interesting topic in both experimental measurements and numerical simulations. The ricochet of solid bodies on water is a topic, which can be applied for further interesting problems in engineering like the ditching of airplanes. For cases with high forward velocity of the impacting body, a large fluid domain needs to be considered.

The behavior of solid bodies which ricochet on water surfaces, has been intensively studied in the past (1-5). Analytical ricochet models developed in the past focus on the value of the asymptotic critical angle of ricochet for high velocities (high Fr) - not always applicable for lower impact velocities and low Fr numbers.

The ricochet of projectiles (solid sphere) from an air-water interface was investigated numerically for three different metals and over a limited range of impact velocities and impact angles. This study shows promise in understanding the complex fluid dynamic processes involved. The model predictions for a steel sphere impacts on an air-water interface agree well with the experimental measurements by (4). Results from the simulation were used to provide a correlation of the critical angle of ricochet of a rigid sphere from an air-water interface in the form

$$
\left.\theta_{c r}=f(F r, \sigma)=252.632 \cdot \operatorname{erf}\left(F r^{0.086}\right)-0.89936\right) \cdot \sigma-239.2
$$

The equation is limited for $480<\mathrm{Fr}<90000$ and $7.8<\sigma<2.7$.

\section{REFERENCES}

[1] Soliman AS, Reid SR, Johnshon W. The effect of spherical pro-jectile speed in ricochet off water and sand. . Int J Mechanical Science. 1976;18:279-84.

[2] Birkhoff G, Birkhoff GD, Bleick WE, Handler EH, Murnaghan D, Smith TL. Ricochet off Water. AMP Memo 424M 1944.

[3] Richardson EG. The Impact of Solid on a Liquid Surface. Proc Phys Soc. 1948;61(4):352-67.

[4] Johnson W, Reid SR. Ricichet of Spheres off Water. Journal of Mechanical Engineeering Science. 1975;17(2):71-81.

[5] Hutchings IM. The ricochet of spheres and cylinders from the surface of water. . Int J Mech Sci. 1976;18:241-7.

[6] Flower S. Hell of a Bomb: How the Bombs of Barnes Wallis Helped Win the Second World War. : Tempus Publishing, Stroud, UK; 2002.

[7] Rayleigh. L. Phil Mag. 1876;2(430).

[8] Podesta M. Bouncing steel balls on water. Physics Education. 2007;42(5).

[9] Mirshak R, Beech T. Estimating Ricochet Hazard Zones at Sea. Journal of Defense Modeling and Simulation: Application, Methodology, Technology. 2018;15:399-413.

[10] Kim YK, Choi WC. Ricochet of Spheres on Sand of Various Temperature. Defence Science Journal. 2018;68(2). 
[11] Park M-S, Jung Y-R, Park W-G. Numerical study of impact force and ricochet behavior of high speed water-entry bodies. Computers \& Fluids. 2003;32(7):939-51.

[12] Guoming C, Jinfu F, Junhua H, Yongli L, An L. The influence of initial conditions of water-entry on ricochet phenomenon. Fluid Dynamics Research. 2017;49(4).

[13] Omidvar P, Farghadani O, Nikeghbali P. SPH for impact force and ricochet behavior of water-entry bodies. International Journal of Modern Physics C. 2017;28(10).

[14] LSTC. LS-DYNA Theory Manual. 2016:77-91.

[15] Segletes SB. A Rod Ricochet Model, ARL-TR-3257. Army Research Laboratory. 2004:1 - 56.

[16] Segletes SB. A model for rod ricochet. International Journal of Impact Engineering 2006;32:1403-39.

[17] Segletes SB. Further development of a model for rod ricochet. International Journal of Impact Engineering. 2007;34:899-925.

[18] Farouk B, Segletes SS. Ricochet of High Speed Aluminum Projectiles from a Steel Plate 2016 International Mechanical Engineering Congress \& Exposition; Paper Number: IMECE2016-65164; ; Phoenix Arizona, USA2016.

[19] De Jonquières E. Comptes Rendus. 1883;97:1278.

[20] DeVuyst T, Seidl M, Campbell Jc, L. P, Vignjevic R. Modelling ricochet of a cylinder on water using ALE and SPH methods. Int Jnl of Multiphysics Volume 9 • Number 3 • 2015;3(9).

[21] LSTC. LS-DYNA Keyword Users Manual, Version 971, Livermore Software Technology Corporation, Livermore CA. 2015.

[22] Belytschko T, Ong JS, Liu WK, Kennedy JM. Hourglass control in linear and nonlinear problems. Computer Methods in Applied Mechanics and Engineering. 1984;43(3):25176.

[23] Grüneisen E. Theorie des festen Zustandes einatomiger Elemente. Annalen der Physik. 1912;344:257-306.

[24] Grüneisen E. The State of a Solid Body: National Aeronautics and Space Administration; 1959. 
